\title{
Herança do peso de grãos primários e secundários de aveia ${ }^{(1)}$
}

\author{
Cândida Braga Cabral(2), Sandra Cristina Kothe Milach ${ }^{(2)}$, Leonardo Araripe Crancio $^{(2)}$ e Marcelo Teixeira Pacheco(2)
}

Resumo - Aliar boa qualidade de grãos às variedades com alto rendimento, ciclo curto e adaptação é um dos objetivos dos programas de melhoramento de aveia no sul do Brasil. O peso dos grãos tem sido um dos critérios utilizados para determinar essa qualidade; porém, para melhor manipular o peso dos grãos nos programas de melhoramento, é necessário o estudo de suas bases genéticas em germoplasma adaptado de aveia. Este trabalho foi realizado com o objetivo de estudar a herança dos caracteres peso de grãos primários e secundários da aveia. Para isso, foram pesadas amostras de 20 grãos primários e secundários de um número variável de plantas nas gerações $\mathrm{P}_{1}, \mathrm{P}_{2}, \mathrm{~F}_{1}, \mathrm{~F}_{2}$ e $\mathrm{F}_{3}$ de cinco cruzamentos de aveia. Com esses dados, foram obtidas as distribuições de freqüência, variâncias, os efeitos gênicos predominantes, e estimados os valores de herdabilidade no sentido amplo, e usando regressão genitorprogênie. Os resultados mostraram que existe variabilidade em progênies precoces no peso de grãos primários e secundários, e que aditividade e dominância são os efeitos gênicos atuantes. Não foi detectada a presença de genes maiores para a expressão dessas características. Além disso, variações contínuas em $\mathrm{F}_{2}$ e herdabilidades baixas a moderadas indicam que seleção amena pode ser aplicada em gerações iniciais.

Termos para indexação: Avena sativa, progênie, variação genética, herdabilidade, melhoramento vegetal.

\section{Inheritance of primary and secondary oat grain weight}

\begin{abstract}
The development of varieties with high grain physical quality, yield and adaptation is one of the main objectives of the oat breeding programs in the South of Brazil. Grain weight is one of the criteria used to determine oat quality and, in order to define the best strategies for the improvement of this trait, it is important to study its genetic basis. Until now, studies of this nature have not been conducted with the Brazilian oat genotypes. This work was carried out with the objective of studying the inheritance of primary and secondary oat grain weight. Samples of 20 primary and secondary grains of a variable number of plants from the generations $\mathrm{P}_{1}, \mathrm{P}_{2}, \mathrm{~F}_{1}, \mathrm{~F}_{2}$ and $\mathrm{F}_{3}$ from five crosses were weighted. From these data, frequency distributions, variances and the predominant gene effects were obtained and heritability values were estimated in the broad sense and using the parent-offspring regression. The results showed that there is variability in early generations for the weight of primary and secondary grains and that additive and dominance are the main acting gene effects. The presence of major genes was not detected in the expression of these traits. Continuous variation in the $\mathrm{F}_{2}$ generation and low to moderate heritabilities indicate that low selection pressures are recommended in early generations.
\end{abstract}

Index terms: Avena sativa, progeny, genetic variation, heritability, plant breeding.

\section{Introdução}

O interesse pela cultura da aveia (Avena sativa L.) por parte dos agricultores vem crescendo no Sul do

\footnotetext{
${ }^{(1)}$ Aceito para publicação em 8 de dezembro de 2000. Extraído da Dissertação de Mestrado apresentada pelo primeiro autor à Universidade Federal do Rio Grande do Sul (UFRGS), Porto Alegre, RS.

(2)UfRGS, Dep. de Plantas de Lavoura, Caixa Postal 776, CEP 91501-970 Porto Alegre, RS. E-mail: cbcabral@ig.com.br, milach@vortex.ufrgs.br, marpac@vortex.ufrgs.br
}

Brasil. Neste contexto, os programas de melhoramento locais têm tido importante papel, por disponibilizarem aos produtores variedades com alto potencial de rendimento de grãos, ciclo curto, e ampla adaptação. Contudo, cada vez mais destaca-se a necessidade de as variedades possuírem, além das características citadas, grãos de boa qualidade.

Diversos critérios têm sido utilizados para a determinação da qualidade dos grãos de aveia, mas não há consenso entre os pesquisadores quanto aos mais adequados. Os principais critérios têm sido peso do 
hectolitro, porcentagem de cariopse ou porcentagem de casca, proporção de grãos primários, secundários e terciários, proporção entre grãos grandes (moáveis) e pequenos (não moáveis) e peso do grão (Bothona, 1997).

Kolb et al. (1990) determinaram que genótipos de aveia de maior rendimento também apresentavam maior peso do grão, e estimaram que $92,8 \%$ da soma de quadrados dos efeitos genéticos eram devidos aos efeitos aditivos, enquanto somente 3,8\% eram devidos a efeitos não aditivos. Assim, devido à sua herança genética mais simples que rendimento de grãos, o caráter peso de grãos foi sugerido pelos autores como um critério de seleção indireta para aumentar o potencial de produtividade de grãos. Por outro lado, as correlações entre rendimento e peso de grãos não foram consistentes, sendo estimadas em 0,51 e 0,71 em relação aos genótipos parentais, e apenas 0,13 na geração $F_{3}$. Pixley \& Frey (1992) encontraram alta herdabilidade quanto ao peso de grãos e valores médios de herdabilidade relativos à porcentagem de cariopse. Do mesmo modo, Chapko et al. (1991) encontraram elevada herdabilidade no sentido amplo em relação ao peso de grãos de aveia. Por outro lado, Jones \& Frey (1962), citado por Marshall \& Shaner (1992), encontraram um valor intermediário de herdabilidade referente a peso de grãos nessa espécie. Os mesmos autores relataram que Murphy \& Frey (1962), estudando gerações $F_{2}$ e $F_{3}$ de 12 cruzamentos em aveia, obtiveram valor médio de herdabilidade de $36 \%$ em relação à característica peso de grãos, mas com variações superiores a $60 \%$. Wesenberg \& Shands (1973) observaram alta herdabilidade no sentido amplo em cinco componentes da qualidade de grãos de aveia. De modo geral, os valores estavam entre 0,71 e 0,89 em relação ao peso dos grãos primários.

Para a definição de estratégias de ação para o melhoramento dessas características, é fundamental o estudo das suas bases genéticas, e até o momento não existe registro de trabalhos desta natureza com germoplasma brasileiro de aveia.

Este trabalho teve como objetivo estimar o modo de herança e a herdabilidade dos caracteres peso de grãos primários e secundários de aveia.

\section{Material e Métodos}

Foram utilizados quatro genótipos de aveia, sendo três cultivares elite do Programa de Melhoramento Genético de Aveia da Universidade Federal do Rio Grande do Sul (UFRGS) e uma cultivar elite proveniente de outro programa (Tabela 1). Esses genótipos foram selecionados com base na análise de dados do peso de mil grãos (PMG) e peso do hectolitro (PH), obtidos dos Ensaios de Cultivares Recomendadas e Sul-brasileiro, de 1995 (Federizzi et al., 1996a, 1996b; Floss et al., 1996). Os genótipos selecionados representavam as classes baixa, intermediária e alta, com relação a essas características.

Nos anos de 1995, 1996 e 1997 foram realizados cruzamentos entre esses genótipos e os híbridos cultivados para obtenção de sementes nas gerações $F_{1}, F_{2}$ e $F_{3}$.

Em 1998, um experimento contendo os genitores e as gerações $F_{1}, F_{2}$ e $F_{3}$, foi conduzido na Estação Experimental Agronômica da UFRGS (EEA/UFRGS) em Eldorado do Sul, RS. Essa região está situada na região fisiográfica da Depressão Central, a 305'52" de latitude Sul e 51039'8" de longitude Oeste, com altitude média de $46 \mathrm{~m}$. O solo pertence à Unidade de Mapeamento São Jerônimo, classificado como Podzólico Vermelho-Escuro; o clima da região é subtropical úmido, com boa distribuição de chuvas.

A fertilidade foi corrigida conforme a análise do solo e recomendações da Rede Oficial de Laboratórios de Análise do Solo. Durante a condução do experimento no campo foram adotadas as técnicas culturais recomendadas para a cultura da aveia, visando à eliminação de ervas daninhas e redução da incidência de pragas, moléstias fúngicas e insetos.

O delineamento experimental foi o de blocos inteiramente casualizados. A semeadura foi feita manualmente, em 29 de maio, e as parcelas das gerações $\mathrm{P}_{1}$ e $\mathrm{P}_{2}$ consistiram de duas linhas de $3 \mathrm{~m}$ de comprimento relativos a cada pai, com espaçamento de $0,20 \mathrm{~m}$ entre linhas e $0,15 \mathrm{~m}$ entre plantas, distribuídas ao longo dos blocos. Nas gerações seguintes foram utilizadas 15 linhas por população $F_{2}$, e uma linha $\mathrm{F}_{3}$ de cada planta $\mathrm{F}_{2}$ colhida em 1997. Em $\mathrm{F}_{1}$, o espaçamento entre plantas foi de $0,30 \mathrm{~m}$. A adubação nitrogenada com uréia foi feita em duas épocas, entre a emergência da terceira e quarta folha e entre a emergência da sexta e sétima folha.

As plantas foram acompanhadas durante o desenvolvimento vegetativo, e no florescimento foi realizada a marcação das panículas principais, as quais foram colhidas individualmente, por ocasião da maturação, colocadas ao sol para secar, e mantidas em câmara fria a $10^{\circ} \mathrm{C}$ até o momento da análise. Foram coletadas 30 panículas de cada genitor e entre 65 e 118 panículas nas populações 
$\mathrm{F}_{2}$ dos cruzamentos UFRGS 7 x UFRGS 14, UFRGS 7 x UFRGS 17, UFRGS 14 x UFRGS 17, UFRGS 7 x CTC 3 e UFRGS 14 x CTC 3. Das gerações $F_{3}$, foram coletadas de oito a dez panículas por linha, e utilizadas aproximadamente 60 linhas de cada população dos cruzamentos entre UFRGS 7 x UFRGS 14, UFRGS 7 x UFRGS 17 e UFRGS 14 x UFRGS 17. Posteriormente, cada panícula principal coletada foi debulhada manualmente, e foram amostrados 20 grãos primários e 20 secundários da metade superior da panícula, e pesados em balança digital. Para amostras que não continham número suficiente de grãos, foi aplicada uma regra de três simples, para estimar o peso de 20 grãos a partir do número de grãos disponíveis.

A análise de variância (modelo fixo) e a comparação de médias pelo teste de Duncan $(\alpha=0,05)$ foram realizadas em relação ao peso de grãos primários e secundários.

Para estudo da herança do peso de grãos primários e secundários em aveia e estimativa dos efeitos gênicos, foram analisadas as distribuições de freqüência, obtidas as estimativas das médias e variâncias, e determinados os valores de herdabilidade no sentido amplo, e utilizando a regressão genitor-progênie (b), que é a que mais se aproxima da estimativa no sentido restrito.

As distribuições de freqüência nas gerações $\mathrm{P}_{1}, \mathrm{P}_{2} \mathrm{e}$ $\mathrm{F}_{2}$, em cada um dos cruzamentos avaliados, foram obtidas pelo agrupamento dos dados em classes (Figura 1). Os intervalos de classe foram estabelecidos com base no desvio-padrão médio de cada caráter, de acordo com Steel \& Torrie (1980). Foi utilizado um quarto do desvio-padrão médio, em ambos os caracteres.

A estimativa dos efeitos gênicos foi obtida nos cruzamentos UFRGS 7 x UFRGS 14, UFRGS 7 x UFRGS 17 e UFRGS 14 x UFRGS 17 pelo teste de escala conjunto, proposto por Cavalli (1952), citado por Mather \& Jinks (1982), e que consiste em estimar os parâmetros média (m), aditividade (a) e dominância (d) a partir das médias e variâncias das gerações disponíveis, e comparação pelo qui-quadrado $\left(\chi^{2}\right)$ entre as médias das gerações observadas e estimadas. Para a estimativa da ação gênica, foi considerado:

$\overline{\mathrm{P}}_{1}=\mathrm{m}+\mathrm{a}+\mathrm{i}$
$\overline{\mathrm{P}}_{2}=\mathrm{m}-\mathrm{a}+\mathrm{i}$

$\overline{\mathrm{F}}_{1}=\mathrm{m}+\mathrm{d}$;

$\overline{\mathrm{F}}_{2}=\mathrm{m}+(1 / 2) \mathrm{d}$;

$\overline{\mathrm{F}}_{3}=\mathrm{m}+(1 / 4) \mathrm{d}$,

onde: $\overline{\mathrm{P}}_{1}, \overline{\mathrm{P}}_{2}, \overline{\mathrm{F}}_{1}, \overline{\mathrm{F}}_{2}$ e $\overline{\mathrm{F}}_{3}$ representam a média de cada geração; $m$, a média geral; a, o efeito de aditividade; $d$, o efeito de dominância; i, o efeito epistático de aditividade $\mathrm{x}$ aditividade.

Em dois desses cruzamentos, foi testado o modelo de três parâmetros, dada a disponibilidade de quatro gerações; e no cruzamento UFRGS 7 x UFRGS 17, com cinco gerações, foi testado o modelo de quatro parâmetros, uma vez que o método do teste de escala conjunto permite estimar um número de parâmetros inferior em uma unidade ao número de gerações disponíveis, de modo que o teste de adequação do modelo possa ser feito pelo quiquadrado. A significância dos efeitos estimados pelo teste de escala conjunto foi avaliada pelo teste $t$.

As variâncias de cada caráter foram estimadas para cinco cruzamentos, conforme proposto por Allard (1960):

$\mathrm{VP}=\mathrm{VF}_{2}$;

$\mathrm{VE}=\left(\mathrm{VP}_{1}+\mathrm{VP}_{2}\right) / 2$;

$\mathrm{VG}=\mathrm{VP}-\mathrm{VE}$,

onde: $\mathrm{VP}, \mathrm{VE}, \mathrm{VG}, \mathrm{VP}_{1}, \mathrm{VP}_{2}$, e $\mathrm{VF}_{2}$ representam as variâncias fenotípica, ambiental, genética e das gerações $\mathrm{P}_{1}, \mathrm{P}_{2}$ e $\mathrm{F}_{2}$, respectivamente.

As estimativas de herdabilidade no sentido amplo $\left(\mathrm{h}^{2} \mathrm{a}\right)$ e genitor-progênie (b) foram calculadas segundo as seguintes equações:

$\mathrm{h}^{2}{ }_{\mathrm{a}}=(\mathrm{VP}-\mathrm{VE}) / \mathrm{VP}$ (Allard, 1960);

$\mathrm{b}=$ covariância $\left(\mathrm{F}_{2} \mathrm{~F}_{3}\right) / \mathrm{var} \mathrm{F}_{2}$ (Borém, 1997).

Nas estimativas de $h^{2}$, foram utilizadas as gerações $\mathrm{P}_{1}, \mathrm{P}_{2}$ e $\mathrm{F}_{2}$, semeadas no campo em 1998. Já para o cálculo da herdabilidade genitor-progênie (b), foram utilizadas a geração $F_{2}$ colocada no campo em 1997, e sua respectiva progênie, linhas $F_{3}$ de 1998.

\section{Resultados e Discussão}

Houve diferenças entre as médias dos genitores (Tabela 2), o que indica existir variabilidade entre

Tabela 1. Genótipos, genealogias, peso de mil grãos (PMG) e peso do hectolitro $(\mathrm{PH})$ de aveia.

\begin{tabular}{llcc}
\hline Genótipo & Genealogia & $\mathrm{PMG}^{(1)}$ & $\mathrm{PH}^{(2)}$ \\
\hline UFRGS 7 & $\mathrm{X} 1205 / \mathrm{FLA} 1093$ & $\mathrm{~B}$ & $\mathrm{~B}$ \\
UFRGS 14 & $805165 / / \mathrm{COR}^{2} / \mathrm{CTZ}^{3} /$ Pendek/ ME 1563 & $\mathrm{A}$ & $\mathrm{I}$ \\
UFRGS 17 & $\mathrm{COR}^{2} / \mathrm{CTZ}^{3} / \mathrm{Pendek} / \mathrm{ME} \mathrm{1563//} \mathrm{76-29/76-23}$ & $\mathrm{I}$ & $\mathrm{A}$ \\
$\mathrm{CTC} 3$ & Steele// Coronado $/ \mathrm{Cortez}^{3} / \mathrm{Pendek} / \mathrm{ME} \mathrm{1563}$ & $\mathrm{I}$ & $\mathrm{A}$ \\
\hline
\end{tabular}

(1)A (alto): acima de $30 \mathrm{~g}$; I (intermediário): de 25 a $30 \mathrm{~g}$; B (baixo): abaixo de $25 \mathrm{~g}$ (desaristado). (2) A (alto): acima de $45 \mathrm{~kg} / \mathrm{hL}$; (intermediário): de 40 a $45 \mathrm{~kg} / \mathrm{hL}$; B (baixo): abaixo de $40 \mathrm{~kg} / \mathrm{hL}$ (desaristado). Fonte: Bothona (1997). 

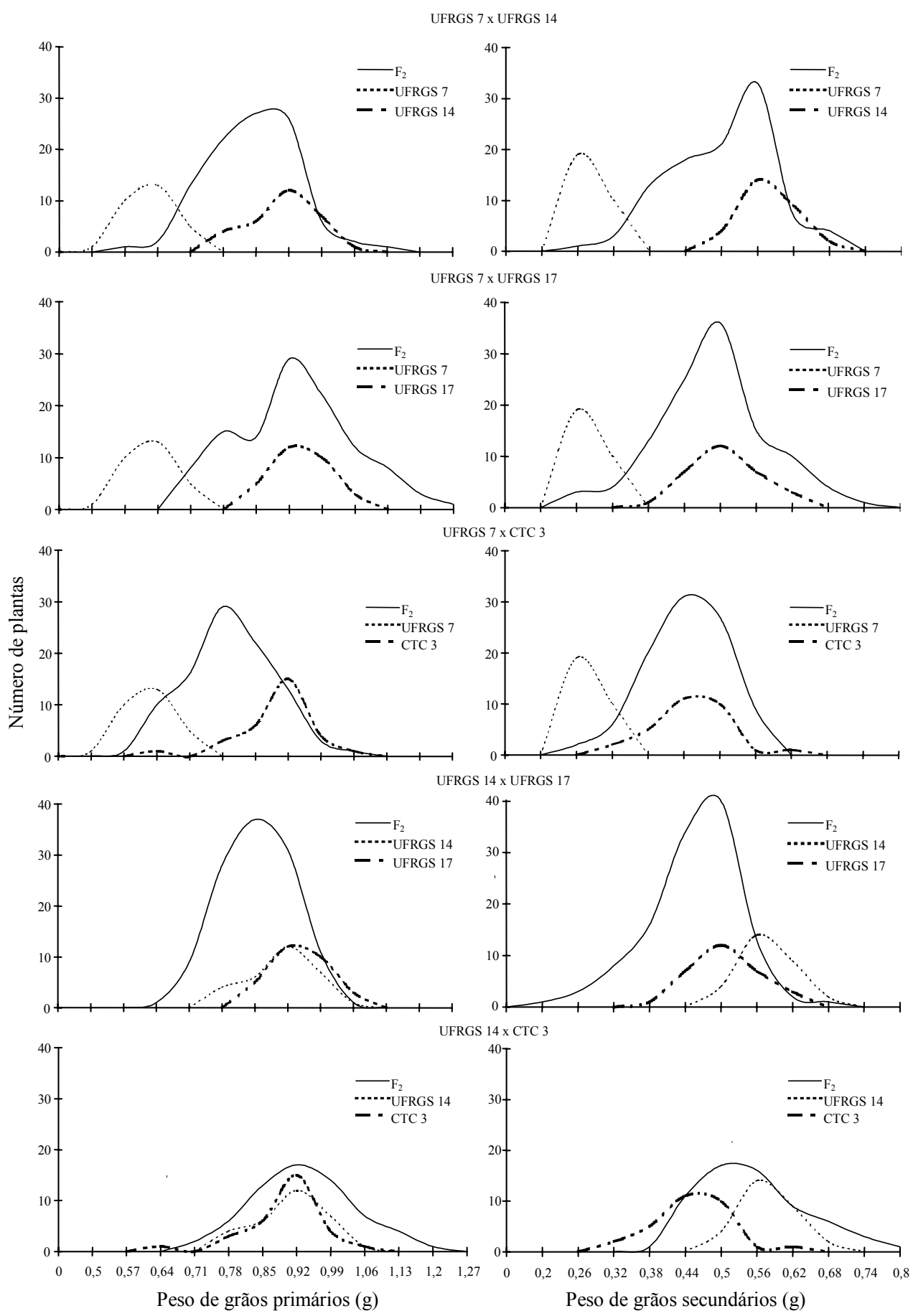

Figura 1. Distribuições de freqüência dos caracteres peso de grãos primários e secundários em duas gerações fixas $\left(\mathrm{P}_{1}\right.$ e $\left.\mathrm{P}_{2}\right)$ e uma geração segregante $\left(\mathrm{F}_{2}\right)$, para cinco cruzamentos de aveia. EEA/UFRGS, 1998.

Pesq. agropec. bras., Brasília, v. 37, n. 1, p. 73-80, jan. 2002 
eles quanto às características peso de grãos primários e secundários em aveia. Apesar da formação de três grupos pelo teste de comparação de médias, os genitores podem ser divididos em dois grupos distintos: o de baixo peso, formado por UFRGS 7, e o grupo de peso intermediário a alto, constituído por CTC 3, UFRGS 14 e UFRGS 17. Isso ficou evidenciado pelas distribuições de freqüência das gerações $\mathrm{P}_{1}$ e $\mathrm{P}_{2}$, que apresentaram graus variados de sobreposição (Figura 1), indicando haver maior ou menor grau de similaridade fenotípica entre os genitores quanto aos caracteres analisados. UFRGS 7, com a menor média de ambas características, foi o genótipo que apresentou menor sobreposição em relação aos outros genitores. Ainda, apesar de UFRGS 14 possuir alto peso de grãos (Tabela 1), não foi o genótipo com o maior peso de grãos primários; contudo, apresentou o maior peso de grãos secundários, o que pode ter levado a um alto peso de grãos (Tabela 2). Segundo Matiello et al. (1997), a diferença entre genótipos cultivados de aveia pode ser devido à presença ou ausência de pressão de seleção, imposta pelo melhoramento, para aumentar o rendimento de grãos e seus componentes do rendimento.

A análise de distribuição de freqüências também evidenciou a dificuldade de estimar o número de genes que controlam as características analisadas, indicando, assim, a presença de genes de pequeno efeito atuando sobre a expressão deles, tendo a geração $\mathrm{F}_{2}$ apresentado variação contínua em todos os cruzamentos com relação às duas características (Figura 1). Não foi observada segregação transgressiva significativa na geração $F_{2}$ dos cruzamentos avalia-

Tabela 2. Médias dos caracteres peso de grãos (g) primários e secundários, dos genótipos de aveia utilizados como genitores das populações analisadas. EEA/UFRGS, $1998^{(1)}$.

\begin{tabular}{lcc}
\hline Genitor & $\begin{array}{c}\text { Grãos } \\
\text { primários }\end{array}$ & $\begin{array}{c}\text { Grãos } \\
\text { secundários }\end{array}$ \\
\hline UFRGS 17 & $0,9122 \mathrm{~A}$ & $0,4781 \mathrm{~B}$ \\
UFRGS 14 & $0,8719 \mathrm{~B}$ & $0,5608 \mathrm{~A}$ \\
CTC 3 & $0,8627 \mathrm{~B}$ & $0,4243 \mathrm{C}$ \\
UFRGS 7 & $0,5834 \mathrm{C}$ & $0,2420 \mathrm{D}$ \\
\hline
\end{tabular}

(1)Médias seguidas pela mesma letra não diferem entre si a $5 \%$ de probabilidade, pelo teste de Ducan. dos, provavelmente porque os genes controlando esses caracteres não estão distribuídos de forma complementar entre os genitores, o que possibilitaria o acúmulo de genes favoráveis ou desfavoráveis nas progênies. A maior variação na distribuição de freqüências foi encontrada nos cruzamentos envolvendo genitores de classes contrastantes, isto é, aqueles com peso intermediário a alto (CTC 3, UFRGS 14, UFRGS 17) com UFRGS 7, de peso baixo de grãos. Por outro lado, menor variação foi observada no cruzamento entre UFRGS 14 e CTC 3, o que era esperado em virtude do comportamento similar desses genitores.

Nos cruzamentos UFRGS 14 x CTC 3 , quanto a ambas as características, e UFRGS 7 x CTC 3, quanto ao peso de grãos primários, a $\mathrm{F}_{2}$ foi intermediária entre os genitores. Já no cruzamento UFRGS 14 x UFRGS 17, houve dominância do genitor de menor peso. Contudo, com exceção dos casos acima, nos demais cruzamentos houve dominância do genitor com maior peso de grãos primários e secundários. Isso se confirma com a análise de média de gerações (Tabelas 3 e 4), onde a dominância só não foi significativa no cruzamento UFRGS 14 x UFRGS 17, em relação a peso de grãos primários, e não foi testada nos cruzamentos envolvendo CTC 3.

Quanto aos efeitos gênicos estudados, relativos às duas características, em três populações (Tabelas 3 e 4), os modelos de três e quatro parâmetros foram aceitos com alta probabilidade, o que mostra que explicam satisfatoriamente a variação nessas características. Os parâmetros aditividade e dominância foram significativos em todas as populações analisadas, exceto no cruzamento UFRGS 14 x UFRGS 17, no qual somente o efeito de aditividade foi significativo quanto ao peso de grãos primários.

No que diz respeito aos efeitos epistáticos, o parâmetro aditividade $\mathrm{x}$ aditividade, medida de todas as interações aditivas $\mathrm{x}$ aditivas entre dois genes, testados no cruzamento UFRGS 7 x UFRGS 17, não foi significativo em nenhum dos caracteres, o que indica que este efeito não está atuando sobre peso dos grãos.

O grau de dominância (d/a) revelou que a magnitude do efeito de dominância, em módulo, foi próximo de um, nos grãos secundários, o que indica que os efeitos de aditividade e dominância praticamente 
se equivalem no controle dessa característica (Tabela 4). No entanto, na característica peso de grãos primários, a importância da dominância foi muito variável, chegando a não-significativa no cruzamento UFRGS 14 x UFRGS 17 (Tabela 3).

Quanto às estimativas de variância e herdabilidade, em ambos os caracteres (Tabela 5), de maneira geral, a variância genética foi superior ou equivalente à variância devida aos efeitos de ambiente. Exceção foi observada no cruzamento UFRGS 14 x UFRGS 17, em que a variância ambiental represen- tou $73 \%$ e $76 \%$ da variância fenotípica total do peso dos grãos primários e secundários, respectivamente. O mesmo ocorreu no cruzamento UFRGS $14 \mathrm{x}$ CTC 3 quanto ao peso de grãos secundários, em que a variância ambiental representou $60,3 \%$ da variação fenotípica.

As estimativas obtidas dos valores de herdabilidade no sentido amplo mostraram magnitude variável em ambos os caracteres. O cruzamento UFRGS 14 x UFRGS 17 apresentou os menores valores de herdabilidade tanto nos grãos primários

Tabela 3. Médias das gerações $\mathrm{P}_{1}, \mathrm{P}_{2}, \mathrm{~F}_{1}, \mathrm{~F}_{2}$ e $\mathrm{F}_{3}$, número de plantas avaliadas em cada geração (entre parênteses), valores dos efeitos gênicos e do teste do qui-quadrado $\left(\chi^{2}\right)$ para o caráter peso de grãos primários, obtidos para três cruzamentos de aveia. EEA/UFRGS, 1998.

\begin{tabular}{cccc}
\hline $\begin{array}{l}\text { Geração ou } \\
\text { efeito gênico }\end{array}$ & UFRGS 7 $\left(\mathrm{P}_{2}\right)$ x UFRGS 14 $\left(\mathrm{P}_{1}\right)$ & UFRGS $7\left(\mathrm{P}_{2}\right) \times$ UFRGS 17 $\left(\mathrm{P}_{1}\right)$ & UFRGS 14 $\left(\mathrm{P}_{2}\right) \times$ UFRGS 17 $\left(\mathrm{P}_{1}\right)$ \\
\hline $\mathrm{P}_{1}$ & $0,8720 \pm 0,0712(30)$ & $0,9122 \pm 0,0638(30)$ & $0,9122 \pm 0,0638(30)$ \\
$\mathrm{P}_{2}$ & $0,5834 \pm 0,0494(29)$ & $0,5834 \pm 0,0494(29)$ & $0,8720 \pm 0,0712(30)$ \\
$\mathrm{F}_{1}$ & - & $0,7618 \pm 0,0604(15)$ & - \\
$\mathrm{F}_{2}$ & $0,8127 \pm 0,0977(100)$ & $0,8993 \pm 0,1267(112)$ & $0,8909 \pm 0,0788(118)$ \\
$\mathrm{F}_{3}$ & $0,7833 \pm 0,0673(56)$ & $0,8160 \pm 0,0708(62)$ & $0,8939 \pm 0,941(57)$ \\
{$[\mathrm{m}]$} & $0,7311 \pm 0,007^{*}$ & $0,7660 \pm 0,007^{*}$ & $0,8926 \pm 0,008^{*}$ \\
{$[\mathrm{a}]$} & $0,1455 \pm 0,008^{*}$ & $0,1687 \pm 0,007^{*}$ & $0,0200 \pm 0,009^{*}$ \\
{$[\mathrm{~d}]$} & $0,1735 \pm 0,025^{*}$ & $0,0764 \pm 0,016^{*}$ & $-0,0027 \pm 0,023$ \\
{$[\mathrm{i}]$} & - & $-0,0172 \pm 0,008$ & - \\
$\mathrm{d} / \mathrm{a}$ & 1,2 & 0,45 & - \\
$\chi^{2}$ & 0,0002 & 0,0202 & 0,000005 \\
$\mathrm{P}^{(1)}$ & 0,99 & 0,89 & 0,99 \\
\hline
\end{tabular}

(1)Probabilidade pelo teste do qui-quadrado. *Significativo a $5 \%$ de probabilidade pelo teste $\mathrm{t}$.

Tabela 4. Médias das gerações $\mathrm{P}_{1}, \mathrm{P}_{2}, \mathrm{~F}_{1}, \mathrm{~F}_{2}$ e $\mathrm{F}_{3}$, número de plantas avaliadas em cada geração (entre parênteses), valores dos efeitos gênicos e do teste do qui-quadrado $\left(\chi^{2}\right)$ para o caráter peso de grãos secundários, obtidos para três cruzamentos de aveia. EEA/UFRGS,1998.

\begin{tabular}{cccc}
\hline $\begin{array}{l}\text { Geração ou } \\
\text { efeito gênico }\end{array}$ & UFRGS 7 $\left(\mathrm{P}_{2}\right) \times$ UFRGS 14 $\left(\mathrm{P}_{1}\right)$ & UFRGS 7 $\left(\mathrm{P}_{2}\right) \times$ UFRGS 17 $\left(\mathrm{P}_{1}\right)$ & UFRGS 14 $\left(\mathrm{P}_{2}\right) \times$ UFRGS $17\left(\mathrm{P}_{1}\right)$ \\
\hline $\mathrm{P}_{1}$ & $0,5608 \pm 0,0757(30)$ & $0,4781 \pm 0,0567(30)$ & $0,5608 \pm 0,0757(30)$ \\
$\mathrm{P}_{2}$ & $0,2420 \pm 0,0303(29)$ & $0,2420 \pm 0,0303(29)$ & $0,4781 \pm 0,0567(30)$ \\
$\mathrm{F}_{1}$ & - & $0,4077 \pm 0,0606(15)$ & - \\
$\mathrm{F}_{2}$ & $0,4728 \pm 0,0846(100)$ & $0,4571 \pm 0,0925(112)$ & $0,4872 \pm 0,0730(118)$ \\
$\mathrm{F}_{3}$ & $0,4651 \pm 0,0543(56)$ & $0,4500 \pm 0,0664(62)$ & $0,4858 \pm 0,0892(57)$ \\
{$[\mathrm{m}]$} & $0,4106 \pm 0,007^{*}$ & $0,3687 \pm 0,006^{*}$ & $0,5156 \pm 0,008^{*}$ \\
{$[\mathrm{a}]$} & $0,1660 \pm 0,007^{*}$ & $0,1228 \pm 0,006^{*}$ & $0,0403 \pm 0,009^{*}$ \\
{$[\mathrm{~d}]$} & $0,1481 \pm 0,023^{*}$ & $0,1002 \pm 0,014^{*}$ & $-0,0615 \pm 0,023^{*}$ \\
{$[\mathrm{i}]$} & - & $-0,0061 \pm 0,006$ & - \\
$\mathrm{d} / \mathrm{a}$ & 0,90 & 0,81 & $-1,53$ \\
$\chi^{2}$ & 0,0014 & 0,0196 & 0,000488 \\
$\mathrm{P}^{(1)}$ & 0,97 & 0,89 & 0,98 \\
\hline
\end{tabular}

(1)Probabilidade pelo teste do qui-quadrado. *Significativo a $5 \%$ de probabilidade pelo teste t. 
(27,6\%) quanto nos secundários $(24,1 \%)$ (Tabela 5). Esses baixos valores de herdabilidade refletem a similaridade genética entre os genitores deste cruzamento. Além disso, baixos valores de herdabilidade indicam maior influência do ambiente, e de acordo com Borém (1997), a característica peso de grãos é definida até 21 dias após a antese, e é influenciada pela disponibilidade de assimilados neste período, podendo apresentar baixa herdabilidade. Isso é reforçado por Thomé (1999), que encontrou que o peso de grãos foi o componente de rendimento mais afetado pela severidade da ferrugem-da-folha em aveia, provavelmente por coincidir seu estádio de desenvolvimento com o período de maior progresso da moléstia no campo. Por outro lado, altos valores de herdabilidade ocorreram, e se concentraram no cruzamento UFRGS 7 x UFRGS 17 , sendo de $79,7 \%$ no peso de grãos primários e $75,9 \%$ no dos secundários. Esse cruzamento foi aquele entre os genitores mais contrastantes quanto ao peso de grãos. Resultados similares foram relatados por Chapko et al. (1991) e Pixley \& Frey (1992).

As estimativas de herdabilidade no sentido amplo indicam que a população proveniente do cruzamento entre UFRGS 7 e UFRGS 17 é aquela em que o progresso genético pode ser obtido mais facilmente com seleção em $\mathrm{F}_{2}$ para ambas as características analisadas, uma vez que apresentou valores superiores em relação às outras populações estudadas. Também nessa população os efeitos de aditividade, que são transmitidos à progênie e fixados nos genótipos homozigotos foram maiores do que os de dominância, o que propicia a seleção em gerações precoces, embora, por ser, possivelmente, um caráter quantitativo, a seleção não seja uma tarefa fácil. Os valores estimados de herdabilidade no peso de grãos secundários foram ligeiramente menores do que no peso de grãos primários, sugerindo que esse caráter pode estar sujeito à maior influência do ambiente. A ordem decrescente dos valores de herdabilidade no sentido amplo nos cinco cruzamentos foi a mesma nos dois caracteres, o que pode ser um indicativo de associação entre eles, o que facilitaria a seleção, pois o incremento em um refletiria no outro.

Os valores estimados de herdabilidade genitorprogênie nos cruzamentos UFRGS 7 x UFRGS 14, UFRGS 7 x UFRGS 17 e UFRGS 14 x UFRGS 17, quanto ao peso de grãos primários foram de $14 \%$, $30 \%$ e $21,5 \%$, respectivamente. Nessa mesma ordem, nos grãos secundários foram de 17,5\%,30,5\% e $42,3 \%$. Observou-se menor magnitude de valores em relação aos valores de herdabilidade no sentido amplo, como era esperado, com exceção do cruzamento UFRGS $14 \times$ UFRGS 17 , em que os dois valores de herdabilidade estimados foram semelhantes nos grãos primários, e a herdabilidade genitor-progênie superou-os no sentido amplo, nos grãos secundários. Isto pode ser devido à diferença entre os métodos utilizados na estimativa dos dois valores de herdabilidade, pois para o cálculo da herdabilidade no sentido amplo foram utilizados dados referentes às gerações parentais e $\mathrm{F}_{2}$, e para herdabilidade genitor-

Tabela 5. Valores de variância fenotípica (VP), genética (VG) e ambiental (VE), herdabilidades no sentido amplo $\left(\mathrm{h}_{\mathrm{a}}^{2}\right)$ e genitor-progênie (b) dos caracteres peso de grãos primários e secundários em cinco cruzamentos de aveia. EEA/UFRGS, 1997 e 1998.

\begin{tabular}{lccccc}
\hline Cruzamento & VP & VG & VE & $\mathrm{h}_{\mathrm{a}}^{2}$ & $\mathrm{~b}$ \\
\hline & \multicolumn{5}{c}{ Peso de grãos primários } \\
UFRGS 7 x UFRGS 14 & 0,0095 & 0,0058 & 0,0037 & 60,7 & 14,0 \\
UFRGS 7 x UFRGS 17 & 0,0160 & 0,0128 & 0,0032 & 79,7 & 30,0 \\
UFRGS 14 x UFRGS 17 & 0,0063 & 0,0017 & 0,0046 & 27,6 & 21,5 \\
UFRGS 7 x CTC 3 & 0,0090 & 0,0053 & 0,0037 & 58,8 & - \\
UFRGS 14 x CTC 3 & 0,0121 & 0,0070 & 0,0050 & 58,6 & - \\
\hline & \multicolumn{7}{c}{ Peso de grãos secundários } \\
UFRGS 7 x UFRGS 14 & 0,0071 & 0,0033 & 0,0038 & 53,2 & 17,5 \\
UFRGS 7 x UFRGS 17 & 0,0085 & 0,0064 & 0,0021 & 75,9 & 30,5 \\
UFRGS 14 x UFRGS 17 & 0,0059 & 0,0014 & 0,0045 & 24,1 & 42,3 \\
UFRGS 7 x CTC 3 & 0,0049 & 0,0023 & 0,0026 & 47,2 & - \\
UFRGS 14 x CTC 3 & 0,0083 & 0,0034 & 0,0050 & 40,5 & - \\
\hline
\end{tabular}


progênie, dados de plantas $F_{2}$ de 1997 e respectivas linhas $\mathrm{F}_{3}$ de 1998.

Uma vez que os valores de herdabilidade variaram conforme o cruzamento, o desafio do melhoramento é determinar as melhores combinações para obter ganho em peso de grãos em gerações iniciais. A prática comum do melhoramento, de cruzamento entre genótipos superiores para a característica-alvo, neste caso, não seria a única alternativa, pois o cruzamento entre os genótipos parentais de maior peso de grãos - UFRGS 14 e UFGRS 17 - apresentou valores de herdabilidade genitor-progênie semelhantes aos dos demais cruzamentos, bem como das progênies $\mathrm{F}_{2}$, com médias similares a estes.

A falta de segregação transgressiva em progênies de cruzamentos entre genitores de alto peso de grãos indica que o melhoramento deve buscar alelos favoráveis de constituição diferenciada em genitores divergentes, para continuar tendo progresso no incremento dessas características, no germoplasma brasileiro de aveia.

\section{Conclusões}

1. Existe variação genética, cujos efeitos significativos são de aditividade e de dominância, em populações segregantes $F_{2}$ de cruzamentos de aveia avaliados quanto ao peso de grãos primários e secundários.

2. Variação contínua em $\mathrm{F}_{2}$ e herdabilidades baixas a moderadas indicam que a seleção em gerações precoces deve ser amena.

\section{Referências}

ALLARD, R. W. Principles of plant breeding. 3. ed. New York: J. Wiley, 1960. 485 p.

BORÉM, A. Melhoramento de plantas. Viçosa, MG: UFV, 1997. 547 p.

BOTHONA, C. R. A. Qualidade do grão de aveia: identificação de características físicas associadas ao rendimento industrial e regiões genômicas. Porto Alegre: UFRGS, 1997. 98 p. Dissertação de Mestrado.

CHAPKO, L. B.; BRINKMAN, M. A.; ALBRECHT, K. A. Genetic variation for forage yield and quality among grain oat genotypes harvested at early heading. Crop Science, Madison, v. 31, p. 874-878, 1991.
FEDERIZZI, L. C.; PACHECO, M. T.; MILACH, S. C. K. Ensaio de cultivares recomendadas de aveia, EEA/UFRGS, Eldorado do Sul, 1995. In: REUNIÃO DA COMISSÃO SUL-BRASILEIRA DE PESQUISA DA AVEIA, 16., 1996, Florianópolis. Anais... Florianópolis: UFSC, 1996a. p. 76-77.

FEDERIZZI, L. C.; PACHECO, M. T.; MILACH, S. C. K. Ensaio sul-brasileiro de linhagens de aveia, EEA/UFRGS, Eldorado do Sul, 1995. In: REUNIÃO DA COMISSÃO SUL-BRASILEIRA DE PESQUISA DA AVEIA, 16., 1996, Florianópolis. Anais... Florianópolis: UFSC, 1996 b. p. 74-75.

FLOSS, E. L.; SCHULZ, J.; TRENTIN, E. A. Qualidade industrial de grãos de cultivares de aveia em Passo Fundo, 1994. In: REUNIÃO DA COMISSÃO SUL-BRASILEIRA DE PESQUISA DA AVEIA, 16., 1996, Florianópolis. Anais... Florianópolis: UFSC, 1996. p. 143-148.

KOLB, F. L.; MARSHAL, H. G.; HILL JUNIOR, R. R. Inheritance of traits associated with grain yield in a spring oat diallel. Crop Science, Madison, v. 30, p. 1023-1029, 1990.

MARSHALL, H. G.; SHANER, G. E. Genetics and inheritance in oat. In: MARSHALL, H. G.; SORRELS, M. E. (Ed.). Oat science and technology. Madison: Crop Science Society of America, 1992. p. 756-775.

MATHER, S. K.; JINKS, J. L. Biometrical genetics. 3. ed. Cambridge: Cambridge University Press, 1982. 396 p.

MATIELLO, R. R.; BARBOSA NETO, J. F.; SERENO, M. J. C. M.; CARVALHO, F. I. F.; PEGORARO, D.; TADERKA, I. Variabilidade genética para peso de grãos e número de espiguetas por panícula em Avena sativa L. e Avena fatua L. Ciência Rural, Santa Maria, v. 27, p. 393-398, 1997.

MURPHY, C. F.; FREY, K. J. Inheritance and heritability of seed weight and its components in oats. Crop Science, Madison, v. 2, p. 509-512, 1962.

PIXLEY, K. V.; FREY, K. J. Genetic interrelations among quality indicators and agronomic traits for oat. Euphytica, Dordrecht, v. 60, p. 149-156, 1992.

STEEL, R. D. G.; TORRIE, J. L. Principles and procedures of statistics. New York: MacGraw-Hill, 1980. $418 \mathrm{p}$.

THOMÉ, G. C. H. Genética e análise molecular da resistência parcial à ferrugem da folha em aveia. Porto Alegre: UFRGS, 1999. 127 p. Tese de Doutorado.

WESENBERG, D. M.; SHANDS, H. L. Heritability of oat caryopsis percentage and other grain quality components. Crop Science, Madison, v. 13, p. 481-484, 1973. 